\title{
Queen dominance and worker policing control reproduction in a threatened ant
}

\author{
Jürgen Trettin ${ }^{1 *}$, Monika Haubner $^{1}$, Alfred Buschinger ${ }^{2}$ and Jürgen Heinze ${ }^{1}$
}

\begin{abstract}
Background: Efficient division of reproductive labor is a crucial characteristic of social insects and underlies their ecological and evolutionary success. Despite of the harmonious appearance of insect societies, nestmates may have different interests concerning the partitioning of reproduction among group members. This may lead to conflict about reproductive rights. As yet, few studies have investigated the allocation of reproduction among queens in multi - queen societies ("reproductive skew"). In the ant Leptothorax acervorum, reproductive skew varies considerably among populations. While reproduction is quite equally shared among nestmate queens in most populations from boreal Eurasia (low skew), colonies from populations at the edge of the species' range are characterized by "functional monogyny," i.e., high skew. The proximate mechanisms underlying high skew, in particular how workers influence which queen lays eggs, are not well understood. We investigated the behavior of queens and workers in functionally monogynous colonies of L. acervorum from two mountain ranges in central Spain.

Results: We provide evidence for both queen and worker influence on the outcome of conflict over reproduction in colonies of $L$. acervorum from Spain. The patterns of queen - queen aggression and worker - queen grooming and feeding after hibernation allowed predicting, which queen later began to lay eggs. In contrast, worker aggression towards queens was not clearly associated with a queen's future reproductive success. Queen - queen and worker - queen aggression differed in quality: queens typically engaged in ritualized dominance behavior, such as antennal boxing, while workers also attacked queens by biting and prolonged pulling on their legs and antennae. In several cases, overt worker aggression led to the expulsion of queens from the nest or their death.

Conclusion: We conclude that queens of $L$. acervorum from Spain establish rank orders by ritualized dominance interactions, such as antennal boxing. Workers may reinforce these hierarchies by preferentially feeding and grooming high ranking queens and attacking lower ranking queens. Aggressive worker policing may thus stabilize functional monogyny. Optimal skew models predict that high skew in ants is associated with high dispersal costs. In central Spain, L. acervorum is restricted to small patches at higher elevations, which presumably makes dispersal and colony founding difficult. Because of the ecological requirements of L. acervorum and the predicted large impact of global change on central Spain, the functionally monogynous populations of this ant must be considered as threatened.
\end{abstract}

\section{Background}

Efficient division of reproductive labor is one of the key characteristics of social insects (e.g., honeybees, ants, and wasps) and underlies their enormous evolutionary success. Despite of the harmonious appearance of their societies, who reproduces and who does not is often

\footnotetext{
* Correspondence: juergen.trettin@biologie.uni-regensburg.de

'Biologie I, Universität Regensburg, Universitätsstr. 31, Regensburg, 93053, Germany

Full list of author information is available at the end of the article
}

controversial, and how conflict about reproductive rights is resolved has become focus of both theoretical and empirical research [1-4].

Punishment, policing, and dominance regulate egg laying in societies in which all females are morphologically identical and potentially capable of reproducing [4,5]. In species with a clear queen-worker diphenism, workers normally refrain from laying eggs in response to the odor of a fertile queen [6,7], presumably because they otherwise risk to be attacked by their nestmates. Worker
C Biomed Central

() 2011 Trettin et al; licensee BioMed Central Ltd. This is an Open Access article distributed under the terms of the Creative Commons Attribution License (http://creativecommons.org/licenses/by/2.0), which permits unrestricted use, distribution, and reproduction in any medium, provided the original work is properly cited. 
altruism in insect societies therefore can be considered to be "enforced" at least in part [8].

Comparatively little is known about another type of conflict, the one about the partitioning of reproduction when colonies contain multiple queens. In facultatively polygynous species, egg laying rates and genetic maternity assignments usually suggest a more or less equal contribution of queens to the egg pile and queens do not interact aggressively ("low reproductive skew"; [9-13]). Brood from individual queens may differ in its propensity to develop into sexuals, but this is not due to social interactions among queens [14].

High reproductive skew, i.e., a highly unequal partitioning of reproduction, has as yet been described for only a handful of species ("functional monogyny"; [9]). For example, in Leptothorax gredleri and related species, nestmate queens violently antennate and bite one another and form social hierarchies, in which only the top - ranking queen begins to reproduce [15-18]. At a later stage, subordinate queens may be attacked and expelled by workers [15-18]. This resembles the elimination of surplus queens in founding associations $[19,20]$ and polygynous species (e.g., [17]). In accordance with models of optimal skew [21], functional monogyny is associated with patchy habitat in which solitary nest founding is costly [22].

In the Holarctic ant Leptothorax acervorum, reproductive skew appears to vary with habitat characteristics. $L$. acervorum is widely distributed over large parts of the northern hemisphere $[23,24]$. Colonies are facultatively polygynous in the extended coniferous forests of Central Europe and Siberia [9-13], but functionally monogynous where they are only patchily distributed, i.e., on sunexposed slopes in Alaska, in light clearings in Hokkaido, and at the southern limit of its range in mountainous areas in central Spain [18,25-28].

Functional monogyny appears to be based on queen dominance interactions and fighting in colonies from Alaska [25] and Hokkaido [18]. However, a recent study suggested that queen-queen interactions are rare in the population from central Spain and that instead worker aggression regulates which queen may lay eggs [29]. Here, we document that both queen dominance and worker policing contribute to the regulation of reproduction in L. acervorum from central Spain.

\section{Results}

Details on the origin and composition of colonies used in this study are given in Table 1 . All queens $(n=35)$ used in the analysis had sperm in their spermathecae. As expected from previous dissections, in each colony only a single queen had fully active ovaries with elongated ovarioles and corpora lutea. Several other queens had partly elongated ovarioles showing traces of previous, temporary egg production. However, their ovaries appeared to have reverted to an inactive state (Table 2). The colonies SA 03 and SA 88 were observed (Table 1) but their queens could not be dissected. Consequently, both colonies were removed from statistical analysis.

Casual observations had already indicated queen queen aggression directly after collecting in fall. More detailed studies after artificial hibernation corroborated this result: aggressive interactions among queens occurred in 11 out of 12 studied colonies from $S^{\text {ra }}$ de Albarracin and $\mathrm{S}^{\text {ra }}$ de Gúdar (Figure 1 and Additional File 1). In all colonies, we in addition observed worker aggression towards queens. In total, queens received $53 \%$ of attacks from other queens (median and quartiles per queen $0.12,0.0,0.9$ attacks per hour). Workers were responsible for $47 \%$ of the attacks toward queens (median and quartiles per queen: 0.36, 0.12, 1.16 attacks per hour). In addition to the antagonistic behavior, we also observed sociopositive interactions (grooming and feeding). The observed level of grooming and trophallaxis received by queens ranged from zero to 2.75 events $h^{-1}$ (median, quartiles per queen: 0.7, 0.44, 1.33 acts per hour). The quality of queen - queen and worker - queen antagonism differed considerably. Queens were significantly more often pulled by workers than by other queens (Figure 2, Mann - Whitney U test: $U=16, N_{1}=$ $\left.N_{2}=10, P=0.008\right)$. We found a similar trend for differences in biting (Figure 2, $U=27.5, P=0.093$ ). In contrast, there was no significant difference between queens and workers in the frequency of antennal boxing (Figure 2, $U=43, P=0.61$ ) and mandible threats (Figure 2, $U$ $=43, P=0.63)$. In numerous instances we observed several workers simultaneously pulling on the antennae or legs of a queen. This severe pulling occasionally led to expulsion of queens and to the death of three queens from three colonies.

Statistical analysis showed that, over all colonies, future reproductive status of queens was not reliably predicted by worker - queen aggression (logistic regression: likelihood - ratio $-\mathrm{Chi}^{2}=0.05$, d. f. $=1, \mathrm{P}=0.83,31$ queens), but instead by the frequency of sociopositive acts from workers to queens (logistic regression: likelihood - ratio $-\mathrm{Chi}^{2}=11.42$, d. f. $=1, \mathrm{P}<0.001,35$ queens). Furthermore, the individual average dominance index (ADI, [30]) of each queen calculated from queen queen aggression predicted the future reproductive status of a queen (likelihood - ratio $-\mathrm{Chi}^{2}=4.50$, d. f. $=1$, $\mathrm{P}=0.034,29$ queens). These results are corroborated by Scheirer - Ray - Hare tests: worker - queen aggression was not associated with the queens' future reproductive status $(\mathrm{H}=0.06, \mathrm{~d} . \mathrm{f} .=1, \mathrm{P}=0.81)$ in contrast to worker - queen grooming and trophallaxis $(\mathrm{H}=5.61, \mathrm{~d}$. f. $=1, P=0.018)$ and, although at only marginal 
Table 1 Location, composition and observation time for each colony

\begin{tabular}{|c|c|c|c|c|c|c|}
\hline Site & Colony & Location & $\begin{array}{l}\text { Altitude } \\
\text { (in m) }\end{array}$ & $\begin{array}{l}\text { No. } \\
\text { Queens }\end{array}$ & $\begin{array}{l}\text { No. } \\
\text { Workers }\end{array}$ & $\begin{array}{l}\text { Observation } \\
\text { time (in hr) }\end{array}$ \\
\hline $\mathrm{S}^{\mathrm{ra}} \mathrm{de}$ & SA 03 & $40.52506^{\circ},-1.64692^{\circ}$ & 1718 & 5 & $30 \pm 10$ & 8.4 \\
\hline \multirow[t]{8}{*}{ Albarracin } & SA 20 & $40.49877^{\circ},-1.59101^{\circ}$ & 1667 & 4 & 25 & 9.7 \\
\hline & SA 51 & $40.49877^{\circ},-1.59101^{\circ}$ & 1667 & 4 & 30 & 7.0 \\
\hline & SA 68 & $40.59878^{\circ},-1.71198^{\circ}$ & 1683 & 6 & 40 & 8.8 \\
\hline & SA 88 & $40.59878^{\circ},-1.71198^{\circ}$ & 1683 & 5 & $50 \pm 10$ & 7.5 \\
\hline & SA 102 & $40.49877^{\circ},-1.59101^{\circ}$ & 1667 & 6 & 15 & 15.9 \\
\hline & SA 109 & $40.49877^{\circ},-1.59101^{\circ}$ & 1667 & 7 & 20 & 26.8 \\
\hline & SA 125 & $40.59878^{\circ},-1.71198^{\circ}$ & 1683 & 4 & 25 & 10.0 \\
\hline & SA 151 & $40.52447^{\circ},-1.64120^{\circ}$ & 1657 & 6 & 20 & 27.9 \\
\hline $\mathrm{S}^{\mathrm{ra}} \mathrm{de}$ & SG 04 & $40.37121^{\circ},-0.62730^{\circ}$ & 1959 & 5 & 40 & 15.4 \\
\hline \multirow[t]{2}{*}{ Gúdar } & SG 32 & $40.39070^{\circ},-0.66517^{\circ}$ & 2014 & 4 & 15 & 24.8 \\
\hline & SG 40 & $40.38626^{\circ},-0.64362^{\circ}$ & 1958 & 5 & 30 & 20.4 \\
\hline
\end{tabular}

significance, $\operatorname{ADI}(\mathrm{H}=3.03$, d. f. $=1, \mathrm{P}=0.08)$. Both queen aggression (8 out of 560 attacks) and worker aggression (16 out of 572 attacks) led to the expulsion of subordinate queens.

Across all five microsatellite loci, average relatedness of nestmate workers from 10 colonies from $\mathrm{S}^{\text {ra }}$ de Albarracin was $0.67 \pm$ SE 0.06. A linkage analysis revealed significant linkage disequilibrium between the loci LXAGA1 and Myrt3 ( $\mathrm{P}=0.005)$. Therefore, we repeated the relatedness analysis without Myrt3 and obtained a relatedness coefficient of $0.66 \pm 0.05$. Both values are not significantly less than the value expected for full sisters $(0.75 ; \mathrm{t}=-1.489, \mathrm{P}=0.17$ vs. $\mathrm{t}=-1.592, \mathrm{P}$ $=0.15)$. The inbreeding coefficient $(F=0.10 \pm 0.08)$ was not significantly different from zero $(\mathrm{t}=1.25, \mathrm{P}>0.2)$.

Table 2 Mating and reproductive status of queens for all colonies used in the analysis

\begin{tabular}{llllll}
\hline & $\begin{array}{l}\text { No. } \\
\text { Queens }\end{array}$ & & & No. Queens & \\
Colony & Mated & Unmated & UD & Reproductive & $\begin{array}{l}\text { Non- } \\
\text { reproductive }\end{array}$ \\
\hline SA 20 & 4 & 0 & 0 & 2 & 2 \\
SA 51 & 2 & 0 & 2 & 1 & 3 \\
SA 68 & 6 & 0 & 0 & 1 & 5 \\
SA 102 & 2 & 3 & 1 & 1 & 5 \\
SA 109 & 5 & 1 & 1 & 1 & 6 \\
SA 125 & 3 & 1 & 0 & 1 & 3 \\
SA 151 & 4 & 2 & 0 & 1 & 5 \\
SG 04 & 3 & 1 & 1 & 1 & 4 \\
SG 32 & 3 & 1 & 0 & 1 & 3 \\
SG 40 & 4 & 1 & 0 & 1 & 4 \\
\hline
\end{tabular}

Data indicated as the number of queens per category and colony. With the exception of colony SA 20, all colonies had one reproductive queen. As colony SA 20 was observed only for a rather short period ( $9.7 \mathrm{~h}$ over 10 days), the reproductive hierarchy, and hence functional monogyny, could not be fully established. The mating status of several queens that were killed before dissection could not be determined (UD).

\section{Discussion}

Our study provides evidence for the regular occurrence of aggressive interactions among queens in functionally monogynous colonies of the ant L. acervorum from central Spain. Queen - queen aggression leads to the establishment of rank orders, in which the top - ranking queen becomes fertile. Queen dominance behavior, together with additional, unevenly distributed aggressive or sociopositive actions of workers, proximately underlie high reproductive skew and lead to functional monogyny.

Both, the frequency of queen - queen aggression and of grooming and feeding behavior of queens by workers predicted which queen later started to lay eggs. Future reproductive queens typically showed a high level of aggression towards other queens and were frequently groomed and fed by workers. In contrast to queen antagonism, worker aggression towards queens was not associated with future reproductive status. Worker aggression was considerably more overtly aggressive than queen aggression.

Concerning the mechanisms underlying functional monogyny, L. acervorum from central Spain thus is similar to other functionally monogynous ants. Similar aggressive interactions among mated queens were observed previously in L. acervorum from Japan [18] and Alaska [26], and functionally monogynous Leptothorax sp. A, L. gredleri, and Formicoxenus provancheri $[15,16,31]$. In all this cases, antagonistic behavior among queens after hibernation contributes to the establishment of dominance hierarchies in which only the highest - ranking individual is reproducing. Queen queen aggression is commonly complemented by discriminatory treatment of queens by workers. Worker behavior appears to accentuate rank differences, in that workers feed and groom dominant queens more frequently and attack, expel or even kill subordinate 

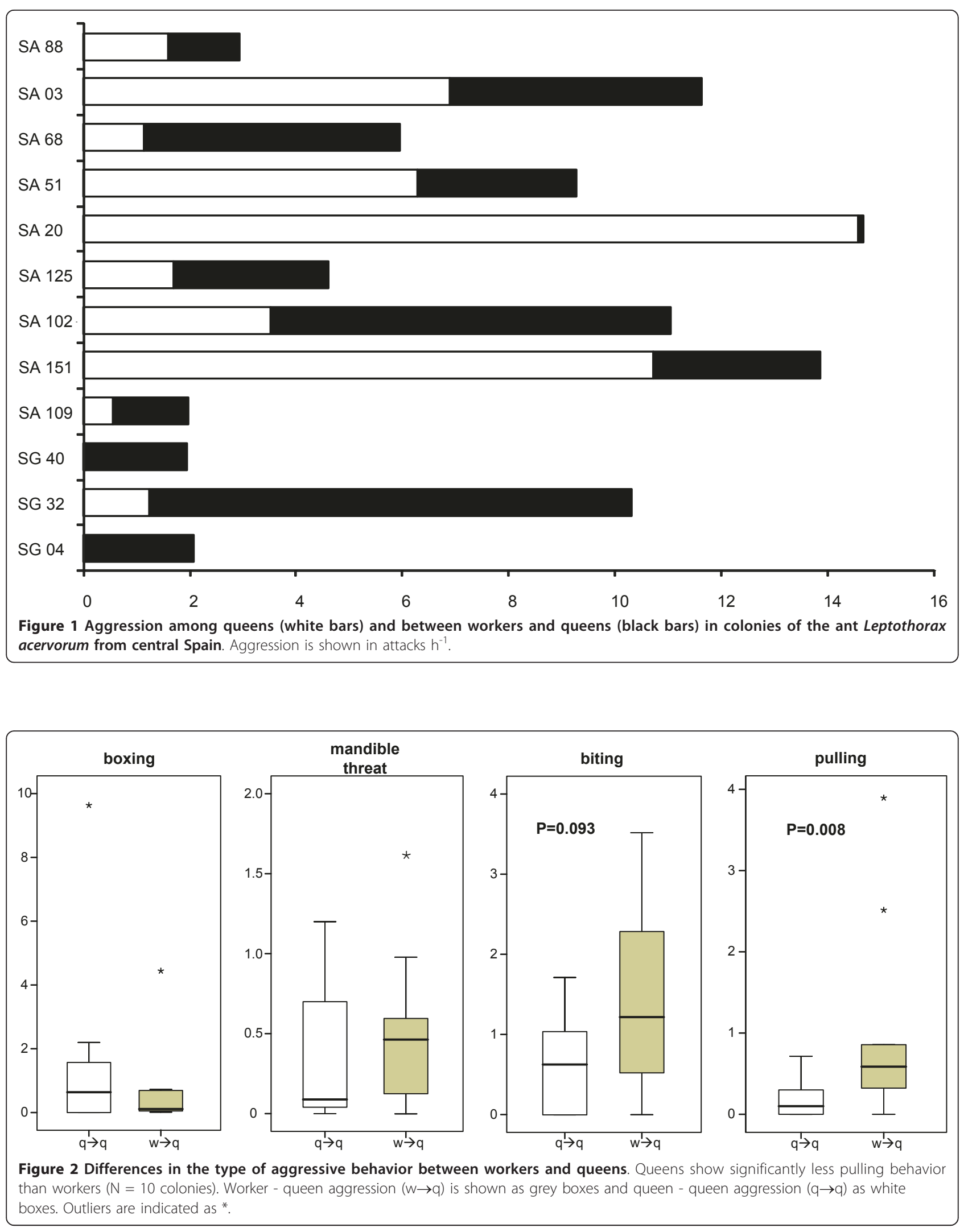
queens. For example, subordinate queens of Leptothorax sp. A and L. gredleri are attacked by workers when reentering the nest after having been expelled by dominant queens $[15,16]$. Similarly, both queen - queen and

worker - queen aggression have been observed in functionally monogynous colonies of $L$. acervorum from Japan and Alaska $[18,26]$. It is therefore not surprising that worker aggression occurs in L. acervorum from Spain. It serves to prevent surplus queens from becoming reproductive [17] and can thus be considered as policing (e.g., [29,32]).

Workers therefore play an important role in the regulation of reproduction, but presumably only after the queens themselves have established rank orders. As suggested by Gill and Hammond [29], workers may act as "agents" of the dominant queen, in that they eliminate rival queens once the hierarchy has formed. Queens of functionally monogynous $L$. gredleri besmear their opponents with Dufour gland secretions, which elicit aggression from workers [16,33]. Similar "punishment" is known from the queenless ant Dinoponera quadriceps [34] and the fighting males of Cardiocondyla [35]. Queen besmearing has not been observed in L. acervorum from Spain, but workers might use more subtle signals or chemical differences among queens to discriminate dominant and subordinate queens. Genetic data suggest that at least in L. gredleri, queens may seek adoption into an alien colony and usurp the top-position in the hierarchy [J.H., unpublished]. Workers appear to support the queen that first becomes reproductive and not necessarily their own mother, similar to the situation in founding associations [19].

Colonies of $L$. acervorum from Central, Western, and Northern Europe are facultatively polygynous (e.g. [9-13]), i.e., the species is functionally monogynous in the periphery of its geographic range. This matches predictions from skew models: marginal areas are suboptimal, and suitable sites for colony founding and nesting are limited. Therefore, such marginal or patchy habitats should favor the development of multiple - queening with less dispersal, higher queen relatedness, higher aggression and higher skew in ant colonies. [21,22]. In the mountains of central Spain, L. acervorum are restricted to humid areas in pine dominated forests at elevations above $1500 \mathrm{~m}$ [27]. Though we did not map the location of colonies in detail, colonies appeared to be restricted to relatively small patches surrounded by large, unpopulated areas. Given that the Sierras of central Spain are not much higher than $2000 \mathrm{~m}$ and expected to be extremely affected by global change [36], it is likely that such patches will become less and less common. Even though functionally monogynous colonies have been found in more northern mountain ranges (JT unpublished), the Spanish high-skew populations of
L. acervorum are probably highly threatened, in contrast to the wide - ranging low - skew populations of boreal Eurasia.

The results of our behavioral study stand in marked contrast to previous observations that worker - queen aggression rather than queen - queen antagonism underlies high reproductive skew [29]. At present we can only speculate about the cause for this discrepancy. First, our study revealed considerable variation in the occurrence of queen - queen aggression among colonies. There may be subtle differences in ecological, behavioral, or genetic properties between the colonies studied by Gill and Hammond [29] and those in our study. Second, and more importantly, the two studies differ in several critical aspects. The behavioral analysis of Gill and Hammond [29] apparently did not include antennal boxing, but focused on more violent aggression, which, as we show above, is more commonly exhibited by workers. Furthermore, they subjected the ants to only six weeks of artificial hibernation. This is much shorter than natural winter and also shorter than the standard hibernation time established for laboratory cultures of Leptothorax ants by Buschinger [37]. Conditions in $S^{\text {ra }}$ de Albarracin and $S^{\text {ra }}$ de Gúdar are harsh and temperatures can fall below $0^{\circ} \mathrm{C}$ during seven months or longer [27]. Leptothorax are active at nest temperatures of $5^{\circ} \mathrm{C}$ for several weeks after the onset of hibernation [38]. Young queens begin to establish hierarchies after mating in late summer and fall [39, see also our study] and a period of six weeks is probably too short to obscure rank differences among queens.

\section{Conclusion}

Our study documents that aggression among nestmate queens occurs in colonies of two functionally monogynous populations of $L$. acervorum from central Spain. Queen queen aggression contributes significantly to the formation of reproductive hierarchies among queens and ultimately to the high reproductive skew in these populations.

In addition, we could show that workers influence skew, especially by differentially feeding and grooming queens. In contrast, the frequency of worker - queen aggression was not associated with a queen's future reproductive success, though worker aggression is certainly involved in later eliminating subordinate queens or driving them out of the nest. The intraspecific variation in reproductive skew makes $L$. acervorum a valuable model system to investigate in more detail the proximate and ultimate mechanisms underlying the evolution of alternative reproductive tactics and strategies in social insects.

\section{Methods}

Ant collection and cultivation

According to detailed field studies by Felke \& Buschinger [27], L. acervorum in central Spain is restricted to 
pine forests at elevations above $1500 \mathrm{~m}$. We therefore focused our study on these previously described collecting sites in the Sierra de Albarracin (September 2008 and May 2009) [27] and also identified similar sites at Sierra de Gúdar (May 2009), both province of Teruel, Spain (Table 1). Colonies were housed in the laboratory in three - chambered plastic boxes $(10 \mathrm{~cm} \times 10 \mathrm{~cm} \times 3$ $\mathrm{cm}$ ) with plaster floor using standard methods [40]. We kept the ants in incubators in near-natural conditions with ten to twelve weeks hibernation (at $12 \mathrm{~h} / 12 \mathrm{~h} 5^{\circ} \mathrm{C}$ / $\left.0^{\circ} \mathrm{C}\right)$, and thereafter at spring conditions $\left(12 \mathrm{~h} / 12 \mathrm{~h} 20^{\circ}\right.$ $\mathrm{C} / 10^{\circ} \mathrm{C}$ ) for the duration of the behavioral studies [37]. Meteorological data [41] and observations suggest that the ants hibernate for an even longer period in the field. Ants were fed with honey, cockroaches and water twice weekly.

\section{Behavioral observations and ovary dissections}

For the behavioral observations, we chose colonies with four to seven queens (Table 1). All queens were individually marked with 30 to $88 \mu \mathrm{m}$ thin metal wires (red enameled, black, green, violet and copper) tied between alitrunk and petiole, petiole and postpetiole, and/or postpetiole and gaster.

Observations were started three days after marking and carried out under spring conditions $\left(20^{\circ} \mathrm{C} / 10^{\circ} \mathrm{C}\right)$. Colonies were directly observed in 20 to 60 -min sessions each under a binocular microscope by scan sampling every 5 minutes and in addition by opportunistic sampling [42]. We chose to observe interactions directly as one of the most frequent aggressive interactions in ants, rapid bouts of antennal boxing, is not easily detected on video recordings. We noted the occurrence of all interactions involving queens (antennal boxing, mandible opening, biting, pulling, stinging/smearing, grooming, and trophallaxis, i.e., exchange of liquid food). Overall, we observed the eight colonies for 580 to $1645 \mathrm{~min}$. Rates of behavior were calculated as the frequency of behavior divided by the total length of time a focal colony was observed (hours, Table 1) and the number of queens per colony. They are indicated as behavioral events per hours and individual.

After the observation period, we killed the queens by freezing them at $-20^{\circ} \mathrm{C}$ and dissected their ovaries under a binocular microscope to check for ovarian status. Dissections were carried out as described in [43]. We noted the presence of maturing oocytes, corpora lutea, and sperm in the spermatheca. Ovarian status was classified following [16].

\section{Statistical analyses}

The antagonistic behavior among queens was used to calculate the average dominance index (ADI, [30]) for each queen per colony. For the analysis of relationships between specific behavioral interactions and the future reproductive state of queens we conducted a logistic regression (reproductive status was binary coded: 'reproductive' $=1$, 'non - reproductive' $=2$ ). We used the Scheirer - Ray - Hare test [44] as an independent method to compare the predictive power between behavioral interactions and the future reproductive state of queens. All unmated queens and queens with undetermined reproductive state were omitted from analysis. The Mann - Whitney U - test was used to test for differences between queen - queen aggressive behavior and worker - queen aggression. All statistical analyses were carried out in SPSS version 17 and JMP 8.01 (SAS, 2009). Scheirer - Ray - Hare test was performed with Excel version 2007.

\section{Genetic analysis}

In addition to the behavioral studies we extracted genomic DNA from 119 workers out of ten colonies from one sample site in the Sierra de Albarracin (SA 64, SA 65, SA 66, SA 68, SA 70, SA 74, SA 76, SA 78 \& SA 88, 12 workers and SA 61, 11 workers) using a CTAB (Cetyltrimethyl ammonium bromide) protocol (modified after [45]). Eleven to twelve workers per colony were genotyped at five polymorphic microsatellite loci that have previously been shown to be informative in this genus: LXAGA1, LXAGA2, LXAGT1 [46], L18 [47], and Myrt3 [48].

PCR conditions were mainly as previously described [45-47] with following annealing temperatures: LXAGA1 at $45^{\circ} \mathrm{C}$, LXAGA2 at $50^{\circ} \mathrm{C}$, LXAGT1, L18 and Myrt3 at $54^{\circ} \mathrm{C}$. Primers were labeled with FAM, HEX, TET fluorescence dyes (Eurofins MWG) and amplification products were analyzed with a capillary sequencer (ABI PRISM 310 Genetic Analyser, Applied Biosystems). We determined allele length using the software GeneScan 3.1 (PE Biosystems). Worker genotypes were used to estimate nestmate relatedness $(r \pm$ SE by jackknife over colonies; [49]) with RELATEDNESS 4.2. In addition, Fisher's method implemented in Genepop 4.0 [50] was used to test for linkage disequilibrium between the five microsatellite loci.

\section{Additional material}

Additional file 1: Fighting queens of $L$. acervorum from central Spain. The movie shows two queens involved in aggressive interactions.

They bite, pull and dry to sting each other. At the same time, one queen is attacked by a worker.

\section{Acknowledgements}

We thank Volker Schmid for help with the statistical analysis in JMP. Supported by Deutsche Forschungsgemeinschaft (He 1623/25). 


\section{Author details}

'Biologie I, Universität Regensburg, Universitätsstr. 31, Regensburg, 93053, Germany. ${ }^{2}$ Rossbergring 18, Reinheim, 64354, Germany.

\section{Authors' contributions}

$A B$ and $J H$ devised the study and took part in field work; JT did most of the collection and, together with $\mathrm{MH}$, the genetic and behavioral studies and analyzed the data. JT and $\mathrm{JH}$ wrote the paper. All authors read and approved the final manuscript.

Received: 31 March 2011 Accepted: 30 September 2011

Published: 30 September 2011

\section{References}

1. Ratnieks FLW: Reproductive harmony via mutual policing by workers in eusocial Hymenoptera. Am Nat 1988, 132:217-236

2. Heinze J, Hölldobler B, Peeters C: Cooperation and conflict in ant societies. Naturwissenschaften 1994, 81:489-497.

3. Heinze J: Reproductive conflict in insect societies. Adv Stud Behav 2004, 34:1-57.

4. Ratnieks FLW, Foster KR, Wenseleers T: Conflict resolution in insect societies. Annu Rev Entomol 2006, 51:581-608.

5. Monnin T, Ratnieks FLW: Policing in queenless ponerine ants. Behav Ecol Sociobiol 2001, 50:97-108.

6. Bourke AFG: Worker reproduction in the higher eusocial Hymenoptera. $Q$ Rev Biol 1988, 63:291-311.

7. Hammond RL, Keller L: Conflict over male parentage in social insects. PloS Biol 2004, 2:e248.

8. Wenseleers T, Ratnieks FLW: Enforced altruism in insect societies. Nature 2006, 444:50.

9. Buschinger A: Mono- und Polygynie bei Arten der Gattung Leptothorax Mayr (Hymenoptera Formicidae). Insectes Soc 1968, 15:217-226.

10. Bourke AFG: Queen behaviour, reproduction and egg-cannibalism in multiple-queen colonies of the ant Leptothorax acervorum. Anim Behav 1991, 42:295-310.

11. Bourke AFG: Indiscriminate egg cannibalism and reproductive skew in a multiple queen-ant. Proc R Soc Lond B 1994, 255:55-59.

12. Heinze J, Lipski N, Hölldobler B, Bourke AFG: Geographical variation in the genetical and social structure of the ant, Leptothorax acervorum. Zoology 1995, 98:127-135.

13. Heinze J, Lipski N, Schlehmeyer K, Hölldobler B: Colony structure and reproduction in the ant, Leptothorax acervorum. Behav Ecol 1995, 6:359-367.

14. Schwander T, Lo N, Beekman M, Oldroyd BP, Keller L: Nature versus nurture in social insect caste differentiation. Trends Ecol Evol 2010, 25:275-282.

15. Heinze J, Smith TA: Dominance and fertility in a functionally monogynous ant. Behav Ecol Sociobiol 1990, 27:1-10.

16. Heinze J, Lipski N, Hölldobler B: Reproductive competition in colonies of the ant Leptothorax gredleri. Ethology 1992, 90:265-278.

17. Lipski N, Heinze J, Hölldobler B: Social organization of three European Leptothorax species (Hym: Formicidae). In Biology and Evolution of Social Insects. Edited by: Billen J. Leuven: Leuven University Press; 1992:287-290.

18. Ito F: Mechanisms regulating functional monogyny in Japanese population of Leptothorax acervorum (Hymenoptera, Formicidae, Myrmicinae): dominance hierarchy and preferential egg cannibalism. Belg J Zool 2005, 135:3-8.

19. Forsyth $A$ : Worker control of queen density in Hymenopteran societies. Am Nat 1980, 116:895-898.

20. Choe JC, Perlman DL: Social conflict and cooperation among founding queens in ants (Hymenoptera: Formicidae). In The Evolution of Socia Behavior in Insects and Arachnids. Edited by: Choe JC, Crespi BJ. Cambridge: Cambridge University Press; 1997:392-406.

21. Keller $L$, Reeve HK: Partitioning of reproduction in animal societies. Trends Ecol Evol 1994, 9:98-102.

22. Bourke AFG, Heinze J: The ecology of communal breeding: the case of multiply-queened leptothoracine ants. Phil Trans R Soc Lond B 1994, 345:359-372.

23. Seifert B: Ameisen Mittel- und Nordeuropas Boxberg: Lutra; 2007.

24. Francoeur A: The ant fauna near the tree-line in northern Québec (Formicidae, Hymenoptera). Nordicana 1983, 47:177-180.
25. Ito F: Functional monogyny of Leptothorax acervorum in northern Japan. Psyche 1990, 97:203-211.

26. Heinze J, Ortius D: Social organization of Leptothorax acervorum from Alaska (Hymenoptera: Formicidae). Psyche 1991, 98:227-240.

27. Felke $M$, Buschinger $A$ : Social organization, reproductive behavior and ecology of Leptothorax acervorum (Hymenoptera, Formicidae) from the Sierra de Albarracin in central Spain. Insectes Soc 1999, 46:84-91.

28. Gill RJ, Arce A, Keller L, Hammond RL: Polymorphic social organization in an ant. Proc R Soc Lond B 2009, 276:4423-4431.

29. Gill RJ, Hammond RL: Workers influence royal reproduction. Proc $R$ Soc Lond $B$

30. Hemelrijk CK, Wantia J, Gygax L: The construction of dominance order: comparing performance of five methods using an individual-based model. Behaviour 2005, 142:1037-1058.

31. Heinze J, Gübitz T, Errard C, Lenoir A, Hölldobler B: Reproductive competition and colony fragmentation in the guest ant Formicoxenus provancheri. Experientia 1993, 49:814-816.

32. Heinze J, d'Ettorre P: Honest and dishonest communication in social Hymenoptera. J exp Biol 2009 212:1775-1779.

33. Heinze J, Oberstadt B, Tentschert J, Hölldobler B, Bestmann HJ: Colony specificity of Dufour gland secretions in a functionally monogynous ant. Chemoecology 1998 8:169-174.

34. Monnin T, Ratnieks FLW, Jones GR, Beard R: Pretender punishment induced by chemical signalling in a queenless ant. Nature 2002, 419:61-65.

35. Yamauchi K, Kawase N: Pheromonal manipulation of workers by a fighting male to kill his rival males in the ant Cardiocondyla wroughtonii. Naturwissenschaften 1992, 79:274-276.

36. Thuiller W, Lavorei S, Araújo MB, Sykes MT, Prentice IC: Climate change threats to plant diversity in Europe. Proc Natl Acad Sci USA 2005, 102:8245-8250.

37. Buschinger A: The role of daily temperature rhythms in brood development of ants of the tribe Leptothoracini (Hymenoptera; Formicidae). In Effects of temperature on ectothermic organisms. Edited by: Wieser W. Berlin: Springer; 1973:229-232.

38. Heinze J, Stahl M, Hölldobler B: Ecophysiology of hibernation in boreal Leptothorax ants (Hymenoptera: Formicidae). Écoscience 1996, 3:429-435.

39. Ortius D, Heinze J: Fertility signaling in queens of a North American ant. Behav Ecol Sociobiol 1999, 45:151-159.

40. Buschinger A: Experimente und Beobachtungen zur Gründung und Entwicklung neuer Sozietäten der sklavenhaltenden Ameise Harpagoxenus sublaevis (Nyl.). Insectes Soc 1974, 21:381-406.

41. Atlas Climático Digital de Aragón. [http://www.opengis.uab.es/wms/ Aragon/index.htm].

42. Martin P, Bateson P: Measuring behaviour: an introductory quide Cambridge: Cambridge University Press; 2007.

43. Buschinger A, Alloway TM: Caste polymorphism in Harpagoxenus canadensis M.R. Smith (Hym., Formicidae). Insectes Soc 1978, 25:339-350.

44. Sokal RR, Rohlf FJ: Biometry: the principles and practices of statistics in biological research New York: W.H. Freeman; 1995.

45. Sambrook J, Russell DW: Molecular cloning: a laboratory manual New York: Cold Spring Harbor Laboratory Press; 2001

46. Bourke AFG, Green HA, Bruford MW: Parentage, reproductive skew and queen turnover in a multiple-queen ant analysed with microsatellites. Proc R Soc Lond B 1997, 264:277-283.

47. Foitzik S, Haberl M, Gadau J, Heinze J: Mating frequency of Leptothorax nylanderi ant queens determined by microsatellite analysis. Insectes Soc 1997, 44:219-227.

48. Evans JD: Parentage analysis in ant colonies using simple sequence repeat. Mol Ecol 1993, 2:393-397.

49. Queller DC, Goodnight KF: Estimating relatedness using genetic markers. Evolution 1989, 43:258-275.

50. Rousset F: Genepop'007: a complete reimplementation of the Genepop software for Windows and Linux. Mol Ecol Resources 2008, 8:103-106.

doi:10.1186/1472-6785-11-21

Cite this article as: Trettin et al:: Queen dominance and worker policing control reproduction in a threatened ant. BMC Ecology 2011 11:21. 